\title{
Extremely High Objective Response Rate of Lenvatinib: Its Clinical Relevance and Changing the Treatment Paradigm in Hepatocellular Carcinoma
}

\author{
Masatoshi Kudo \\ Department of Gastroenterology and Hepatology, Kindai University Faculty of \\ Medicine, Osaka-Sayama, Japan
}

\section{Introduction}

Prof. M. Kudo

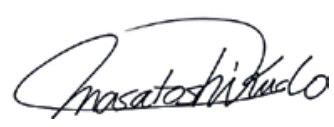

Editor Liver Cancer

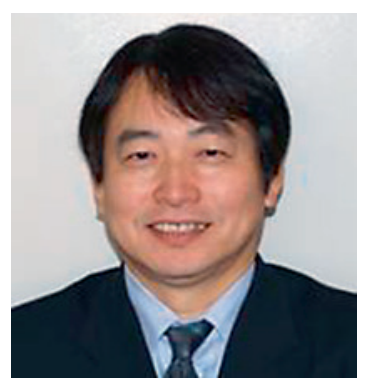

The results of a clinical trial of lenvatinib were published in the Lancet earlier this year [1]. According to the results, the response rate was higher for lenvatinib than for any other known molecular targeted agents in hepatocellular carcinoma (HCC) patients. The response rates based on independent imaging review and investigator review according to the modified RECIST (mRECIST) assessment were extremely high at 40.6 and $24.1 \%$, respectively. The response rate based on independent imaging review according to RECIST 1.1 was also high (18.8\%) (Table 1). The response to locoregional treatment (e.g., transcatheter arterial chemoembolization [TACE] and ablation) is correlated with overall survival (OS). In a meta-analysis of seven studies, Vincenzi et al. [2] showed that the hazard ratio (HR) for OS was 0.39 (95\% confidence interval [CI] 0.26-0.61, $p<0.0001$ ) when comparing responders and nonresponders among 1,352 patients treated with TACE $(n=1,236)$, cryoablation $(n=64)$, and bland transarterial embolization ( $n=57$ ). This excellent HR indicated the correlation between response to locoregional therapy and OS benefit (Fig. 1). It is established evidence that OS benefit is more prominent in responders to locoregional therapy than in nonresponders evaluated by mRECIST; thus, the evidence that objective response measured by mRECIST predicts survival in patients receiving locoregional therapies is currently recommended in the EASL guidelines [3]. Regarding molecular targeted agents, most sorafenib-treated patients show stable disease, demonstrating the survival benefit of sorafenib treatment. However, the asso- 
Table 1. REFLECT study: objective response rate of lenvatinib and sorafenib

\begin{tabular}{|c|c|c|c|c|}
\hline & Lenvatinib $(n=478)$ & Sorafenib $(n=476)$ & Effect size $(95 \% \mathrm{CI})$ & $p$ value \\
\hline \multicolumn{5}{|c|}{ Independent imaging review according to $m R E C I S T$} \\
\hline Objective response, $n(\%, 95 \% \mathrm{CI})$ & $194(40.6,36.2-45.0)$ & $59(12.4,9.4-15.4)$ & OR $5.01(3.59-7.01)$ & $<0.0001$ \\
\hline Complete response & $10(2)$ & $4(1)$ & - & - \\
\hline Partial response & $184(38)$ & $55(12)$ & - & - \\
\hline Stable disease & $159(33)$ & $219(46)$ & - & - \\
\hline Durable stable disease lasting $\geq 23$ weeks & $84(18)$ & $90(19)$ & - & - \\
\hline Progressive disease & 79 (17) & $152(32)$ & - & - \\
\hline Unknown or not evaluable & $46(10)$ & $46(10)$ & - & - \\
\hline Disease control rate, $n(\%, 95 \% \mathrm{CI})$ & $353(73.8,69.9-77.8)$ & $278(58.4,54.0-62.8)$ & - & - \\
\hline \multicolumn{5}{|l|}{ Investigator review according to $\mathrm{mRECIST}$} \\
\hline Objective response, $n(\%, 95 \% \mathrm{CI})$ & $115(24.1,20.2-27.9)$ & $44(9.2,6.6-11.8)$ & OR $3.13(2.15-4.56)$ & $<0.0001$ \\
\hline Complete response & $6(1)$ & $2(<1)$ & - & - \\
\hline Partial response & $109(23)$ & $42(9)$ & - & - \\
\hline Stable disease & $246(51)$ & $244(51)$ & - & - \\
\hline Durable stable disease lasting $\geq 23$ weeks & $167(35)$ & $139(29)$ & - & - \\
\hline Progressive disease & $71(15)$ & $147(31)$ & - & - \\
\hline Unknown or not evaluable & $46(10)$ & $41(9)$ & - & - \\
\hline Disease control rate, $n(\%, 95 \% \mathrm{CI})$ & $361(75.5,71.7-79.4)$ & $288(60.5,56.1-64.9)$ & - & - \\
\hline \multicolumn{5}{|c|}{ Independent imaging review according to RECIST 1.1} \\
\hline Objective response, $n(\%, 95 \% \mathrm{CI})$ & $90(18.8,15.3-22.3)$ & $31(6.5,4.3-8.7)$ & OR $3.34(2.17-5.14)$ & $<0.0001$ \\
\hline Complete response & $2(<1)$ & $1(<1)$ & - & - \\
\hline Partial response & $88(18)$ & $30(6)$ & - & - \\
\hline Stable disease & $258(54)$ & $250(53)$ & - & - \\
\hline Durable stable disease lasting $\geq 23$ weeks & $163(34)$ & $118(25)$ & - & - \\
\hline Progressive disease & $84(18)$ & $152(32)$ & - & - \\
\hline Unknown or not evaluable & $46(10)$ & $43(9)$ & - & - \\
\hline Disease control rate, $n(\%, 95 \% \mathrm{CI})$ & $348(72.8,68.8-76.8)$ & $281(59.0,54.6-63.5)$ & - & - \\
\hline
\end{tabular}

Values are $n(\%)$ unless otherwise indicated.

EASL guidelines recommend that objective response measured by $\mathrm{mRECIST}$ predicts survival in patients receiving locoregional therapies

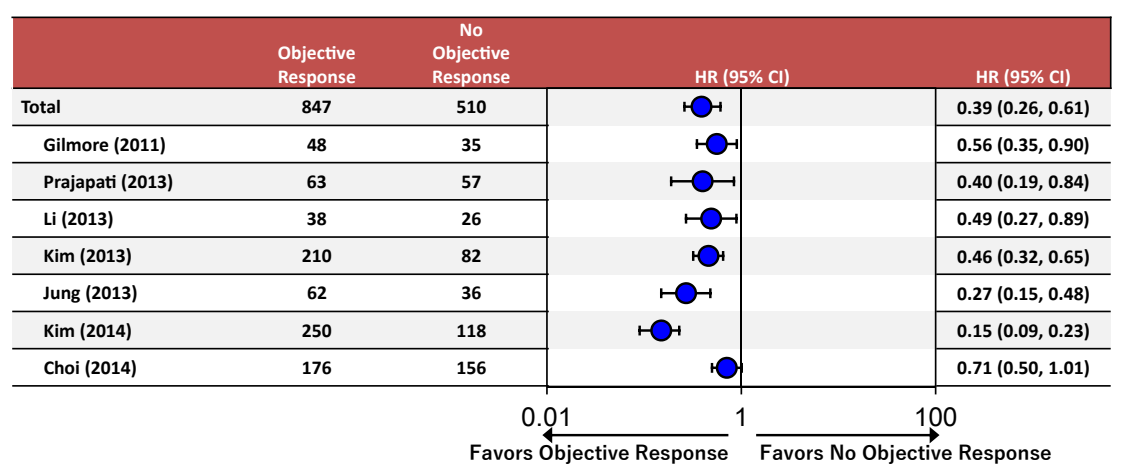

Fig. 1. Correlation between objective response and improved OS in early- or intermediate-stage HCC (from Vincenzi et al. [2]).

ciation between response to molecular targeted agents and improved survival remains unclear. This article reviews recent reports based on retrospective studies and prospective clinical trials of molecular targeted agents with an emphasis on the relationship between response to these agents and improvement of patient survival. 


\section{Liver
Cancer}

\begin{tabular}{l|l}
\hline Liver Cancer 2018;7:215-224 \\
\hline DOI: 10.1159/000492533 & $\begin{array}{l}\text { @ 2018 S. Karger AG, Basel } \\
\text { www.karger.com/lic }\end{array}$ \\
\hline
\end{tabular}

Kudo: Extremely High Objective Response Rate of Lenvatinib: Clinical Relevance

Table 2. Objective response by mRECIST predicts overall survival: retrospective analysis

\begin{tabular}{|c|c|c|c|c|c|c|}
\hline \multirow{2}{*}{$\begin{array}{l}\text { Study, } \\
\text { year }\end{array}$} & \multirow{2}{*}{$\begin{array}{l}\text { Agents } \\
\text { (study design) }\end{array}$} & \multirow{2}{*}{$\begin{array}{l}\text { ORR (mRECIST), } \\
\%(n / N)\end{array}$} & \multicolumn{2}{|c|}{ Median OS, months } & \multirow{2}{*}{$\begin{array}{l}\text { HR } \\
(95 \% \mathrm{CI})\end{array}$} & \multirow[t]{2}{*}{$p$ value } \\
\hline & & & $\begin{array}{l}\text { responder } \\
(\mathrm{CR}+\mathrm{PR})\end{array}$ & $\begin{array}{l}\text { nonresponder } \\
(\mathrm{SD}+\mathrm{PD})\end{array}$ & & \\
\hline $\begin{array}{l}\text { Ronot [4], } \\
2012\end{array}$ & $\begin{array}{l}\text { sorafenib } \\
\text { (retrospective) }\end{array}$ & $28.1(18 / 64)$ & 25.5 & $\begin{array}{r}13.3(\mathrm{SD}) \\
5.7(\mathrm{PD})\end{array}$ & N/A & $<0.001$ \\
\hline $\begin{array}{l}\text { Arizumi [5], } \\
2014\end{array}$ & $\begin{array}{l}\text { sorafenib } \\
\text { (retrospective) }\end{array}$ & $22.8(36 / 158)$ & 25.4 & $\begin{array}{l}7.3(\mathrm{PD}) \\
5.7 \text { (short SD) }\end{array}$ & $\mathrm{N} / \mathrm{A}$ & $<0.0001$ \\
\hline $\begin{array}{l}\text { Edeline [6], } \\
2014\end{array}$ & $\begin{array}{l}\text { sorafenib } \\
\text { (retrospective) }\end{array}$ & $22.6(12 / 53)$ & 18 & 8 & $\mathrm{~N} / \mathrm{A}$ & 0.013 \\
\hline $\begin{array}{l}\text { Takada [7], } \\
2015\end{array}$ & $\begin{array}{l}\text { sorafenib } \\
\text { (retrospective) }\end{array}$ & $13.1(25 / 191)$ & 22.0 & 10.0 & $\mathrm{~N} / \mathrm{A}$ & 0.0117 \\
\hline
\end{tabular}

ORR, objective response rate; OS, overall survival; CR, complete response; PR, partial response; SD, stable disease; PD, progressive disease.

\section{Retrospective Studies of Sorafenib}

Ronot et al. [4] examined 64 sorafenib-treated HCC patients, and found that the median OS was 25.5 months in 18 patients with objective response (objective response rate [ORR] $28.1 \%$ ), 13.3 months in 29 patients with stable disease, and 5.7 months in 29 patients with progressive disease, according to the mRECIST criteria; OS was significantly longer in responders than in nonresponders $(p<0.001)$. Arizumi et al. [5] retrospectively analyzed 158 sorafenib-treated patients, and found significantly better OS in responders (patients with complete response or partial response, 25.4 months) than in patients with short stable disease (5.7 months) and progressive disease (7.3 months) $(p<0.0001)$. Edeline et al. [6] analyzed sorafenib-treated patients with unresectable HCC, and reported a median OS of 18 months in 12 responders (response rate, $22.6 \%$ ), which was significantly longer than the median OS of 8 months in 41 nonresponders $(p=0.013)$. In a retrospective analysis of 191 sorafenibtreated patients, Takada et al. [7] identified 25 responders according to mRECIST, and showed that OS was significantly longer $(p=0.0117)$ in these patients (22 months) than in nonresponders (10 months) (Table 2). However, because these studies were all retrospective analyses, the levels of evidence provided are not high.

\section{Association between Response to Molecular Targeted Agents and Survival Benefit Demonstrated by Prospective Controlled Trials}

Lencioni et al. [8] performed a responder analysis using data from a Phase III trial of brivanib as second-line therapy. Among 226 brivanib-treated patients, 26 were responders according to mRECIST (ORR 11.5\%); OS was 15.0 months in responders, which was significantly longer than the OS of 9.4 months in nonresponders (HR $0.31,95 \%$ CI $0.16-0.60, p<$ 0.001). Multivariable analysis confirmed that objective response evaluated according to mRECIST was a clear independent predictor of survival. Furthermore, the authors reported that survival becomes more favorable with increasing ORR and longer duration of response.

Meyer et al. [9] analyzed pooled data of the Phase II part of two multicenter open-label Phase I and randomized Phase II studies (nintedanib $200 \mathrm{mg}$ twice daily versus sorafenib 400 


\section{Liver Cancer}

\begin{tabular}{|c|c|}
\hline \multicolumn{2}{|c|}{ Liver Cancer 2018;7:215-224 } \\
\hline DOI: 10.1159/000492533 & $\begin{array}{l}\text { (c) } 2018 \text { S. Karger AG, Basel } \\
\text { www.karger.com/lic }\end{array}$ \\
\hline
\end{tabular}

Kudo: Extremely High Objective Response Rate of Lenvatinib: Clinical Relevance

Table 3. Objective response by mRECIST predicts overall survival: results of RCT

\begin{tabular}{|c|c|c|c|c|c|c|}
\hline \multirow{2}{*}{$\begin{array}{l}\text { Study, } \\
\text { year }\end{array}$} & \multirow{2}{*}{$\begin{array}{l}\text { Agents } \\
\text { (study design) }\end{array}$} & \multirow{2}{*}{$\begin{array}{l}\text { ORR (mRECIST), } \\
\%(n / N)\end{array}$} & \multicolumn{2}{|c|}{ Median OS, months } & \multirow[t]{2}{*}{ HR $(95 \%$ CI $)$} & \multirow[t]{2}{*}{$p$ value } \\
\hline & & & $\begin{array}{l}\text { responder } \\
(\mathrm{CR}+\mathrm{PR})\end{array}$ & $\begin{array}{l}\text { nonresponder } \\
(\mathrm{SD}+\mathrm{PD})\end{array}$ & & \\
\hline $\begin{array}{l}\text { Lencioni [8], } \\
2017\end{array}$ & $\begin{array}{l}\text { brivanib } \\
\text { (Phase III RCT) }\end{array}$ & $11.5(26 / 226)$ & 15.0 & 9.4 & $0.31(0.16-0.60)$ & $<0.001$ \\
\hline $\begin{array}{l}\text { Meyer [9], } \\
2017\end{array}$ & $\begin{array}{l}\text { nintedanib + } \\
\text { sorafenib } \\
\text { (Phase II RCT) }\end{array}$ & $15.6(28 / 180)$ & 16.7 & 10.9 & $0.544(0.335-0.881)$ & 0.0122 \\
\hline $\begin{array}{l}\text { Kudo [10], } \\
2018\end{array}$ & $\begin{array}{l}\text { sorafenib } \\
\text { (Phase III RCT) }\end{array}$ & $18.8(18 / 96)$ & 27.2 & 8.9 & $\mathrm{~N} / \mathrm{A}$ & $<0.001$ \\
\hline
\end{tabular}

RCT, randomized controlled trial; ORR, objective response rate; OS, overall survival; CR, complete response; PR, partial response; SD, stable disease; $\mathrm{PD}$, progressive disease; HR, hazard ratio.

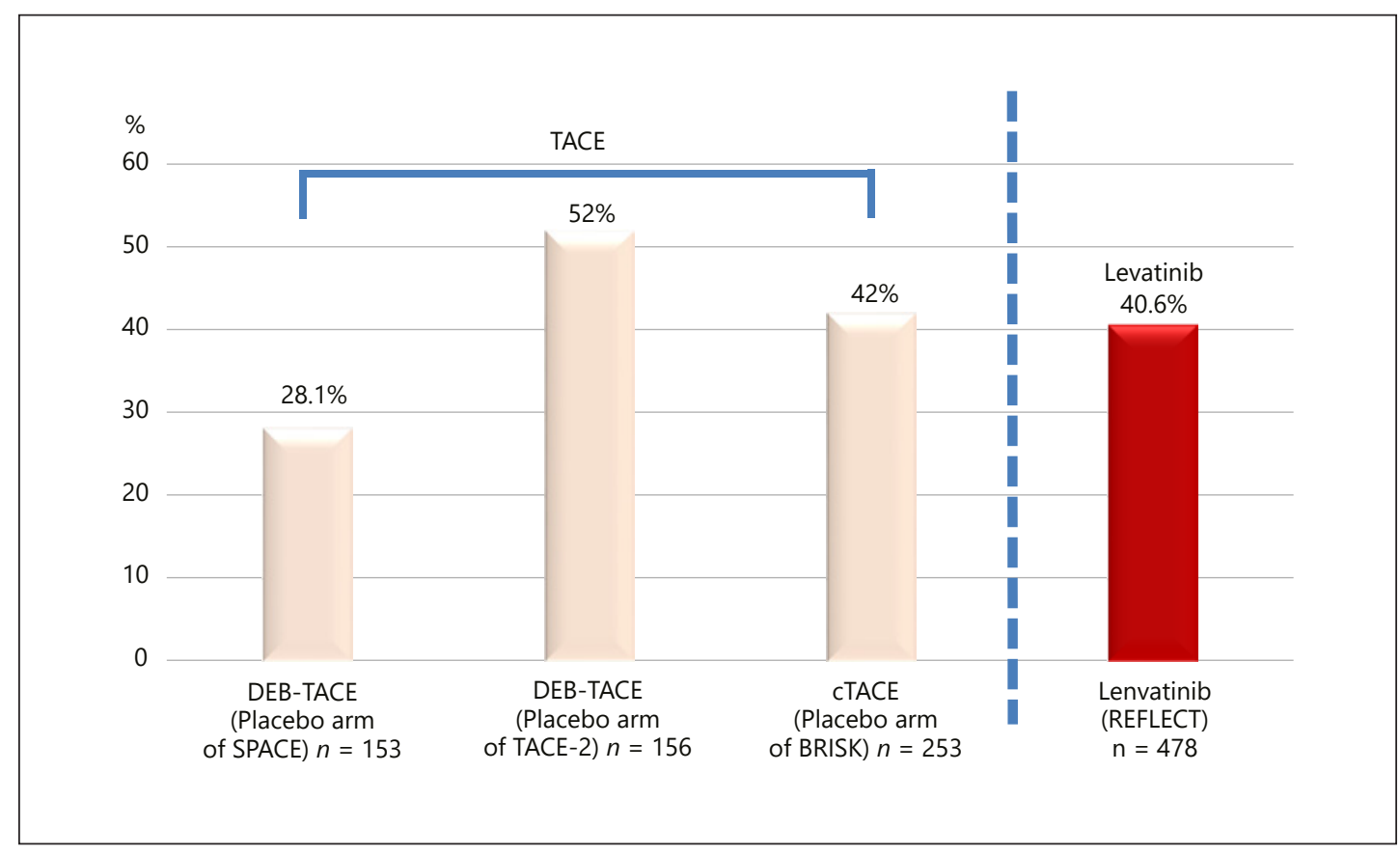

Fig. 2. Objective response rate by mRECIST: TACE and lenvatinib.

mg twice daily) carried out independently in Asia and Europe to examine the association of response (according to RECIST 1.0 or mRECIST) with survival. Of 180 patients, 28 were responders (response rate, 15.6\%), with a median OS of 16.7 months, whereas 152 showed no response and had a median OS of 10.9 months; OS was significantly better in responders than in nonresponders (HR 0.544, 95\% CI 0.335-0.881, $p=0.0122$ ).

Multivariable analysis showed that response according to mRECIST was an independent predictor of survival, albeit only with a trend toward significance (HR 0.62, 95\% CI 0.38-1.01, $p=0.053$ ), roughly supporting the results of the multivariable analysis reported by Lencioni et al. [8]. 
Table 4. Response per mRECIST by independent review analysis

\begin{tabular}{|c|c|c|c|c|}
\hline & \multicolumn{2}{|l|}{ Japan } & \multicolumn{2}{|l|}{ Overall } \\
\hline & $\begin{array}{l}\text { lenvatinib } \\
(n=81)\end{array}$ & $\begin{array}{l}\text { sorafenib } \\
(n=87)\end{array}$ & $\begin{array}{l}\text { lenvatinib } \\
(n=478)\end{array}$ & $\begin{array}{l}\text { sorafenib } \\
(n=476)\end{array}$ \\
\hline Complete response & 2.5 & 1.1 & 2.1 & 0.8 \\
\hline Partial response & 44.4 & 11.5 & 38.5 & 11.6 \\
\hline Stable disease & 32.1 & 47.1 & 33.3 & 46.0 \\
\hline Durable stable disease & 16.0 & 20.7 & 17.6 & 18.9 \\
\hline Progressive disease & 16.0 & 26.4 & 16.5 & 31.9 \\
\hline Not evaluable/unknown & 4.9 & 13.8 & 9.6 & 9.7 \\
\hline Overall response rate & 46.9 & 12.6 & 40.6 & 12.4 \\
\hline $95 \% \mathrm{CI}$ & $36.0-57.8$ & $5.7-19.6$ & $36.2-45.0$ & $9.4-15.4$ \\
\hline$p$ value* & $<0.00001$ & & $<0.00001$ & \\
\hline Disease control rate & 79.0 & 59.8 & 73.8 & 58.4 \\
\hline $95 \% \mathrm{CI}$ & $70.1-87.9$ & $49.5-70.1$ & $69.9-77.8$ & $54.0-62.8$ \\
\hline$p$ value* & 0.00556 & & $<0.00001$ & \\
\hline
\end{tabular}

Values are \% unless otherwise indicated. * nominal.

Kudo et al. [10] conducted the SILIUS study (a prospective controlled trial), and reported that 18 out of 96 patients who received sorafenib monotherapy were responders (response rate, $18.8 \%$ ); OS was 27.2 months in these patients, which was significantly longer than the OS of 8.9 months in nonresponders $(p<0.001)$.

The correlation between response and survival suggests that the quality of evidence is high, because this was clearly proven by responder analysis using the database developed from the above three prospective randomized controlled trials (Table 3). This evidence can be applied to the interpretation of a high lenvatinib response rate. Lenvatinib has a high response rate $(40.6 \%)$, and may therefore offer survival benefit to more than 3 -fold as many patients as other agents.

Responder analysis in the SILIUS study showed a response rate of 36\% in the sorafenib plus arterial infusion chemotherapy group, which was twice as high as that in the sorafenib only group. In addition, the study indicated that the improvement in survival was comparable between the two groups as long as patients responded to the respective therapies. In other words, the survival benefit is more frequently observed in patients who received sorafenib plus arterial infusion chemotherapy because it has a demonstrably higher response rate. Because lenvatinib has an even higher response rate than sorafenib plus arterial infusion chemotherapy, its survival benefit should apply to a higher proportion of patients, suggesting lenvatinib is a potential alternative to arterial infusion chemotherapy. In addition, the ORR of lenvatinib is similar to the world standard ORR of TACE therapy (Fig. 2) [11-13], indicating that it could replace TACE in certain populations of intermediate-stage HCC patients in the very near future.

\section{ORR of Lenvatinib in the Japanese Subpopulation from the REFLECT Trial}

The ORR of lenvatinib in a Japanese subpopulation from the REFLECT trial was reported as $46.9 \%$ (sorafenib, ORR $=12.6 \%$ ), which is considerably higher than the ORR of $40.6 \%$ in the overall population of the REFLECT trial (Table 4) [14]. In addition, the ORR in patients with Barcelona Clinic Liver Cancer (BCLC) intermediate stage was markedly higher $(61.3 \%)$ 

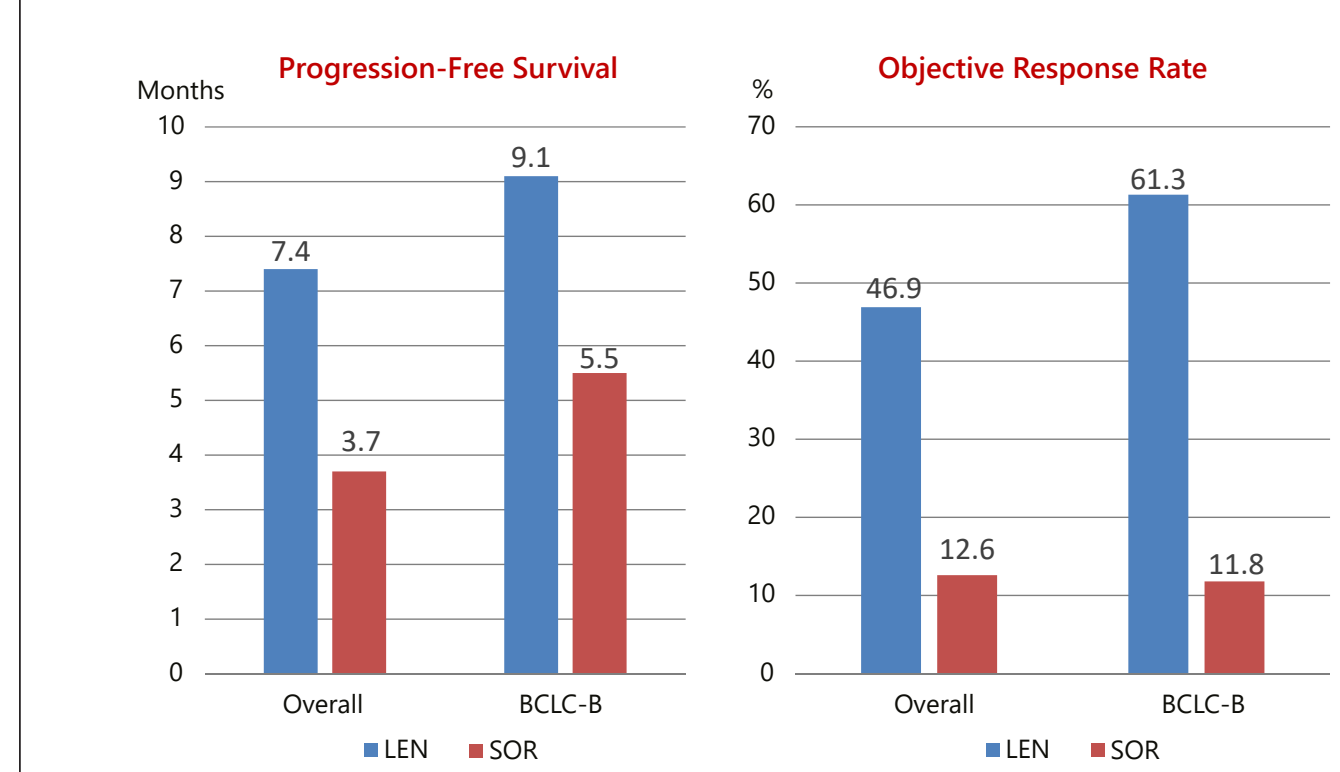

Fig. 3. REFLECT subgroup analysis: Japanese subpopulation showing higher PFS/ORR in BCLC B patients (from Kudo et al. [1]).

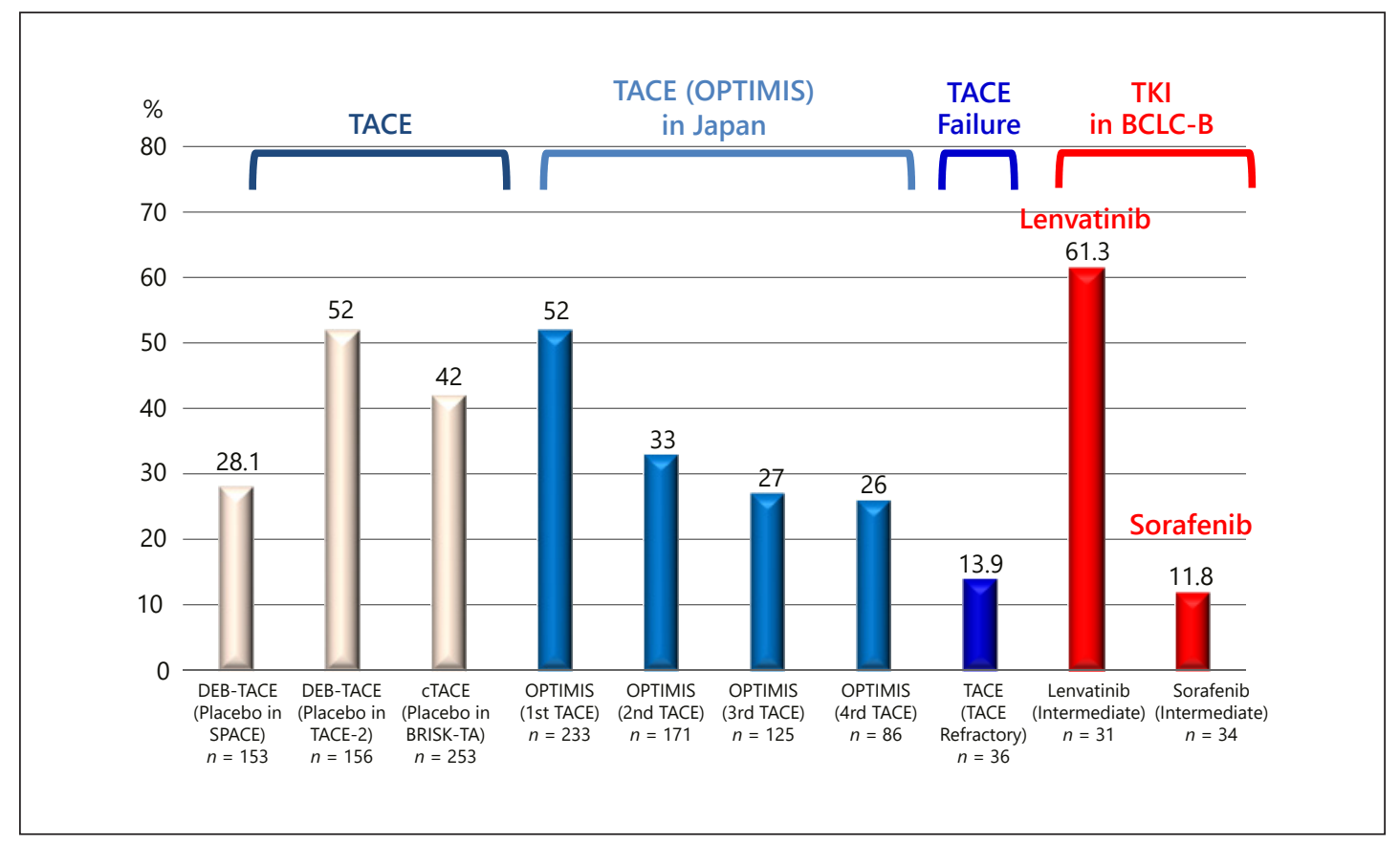

Fig. 4. Objective response rate of TACE and tyrosine kinase inhibitors (TKI). 


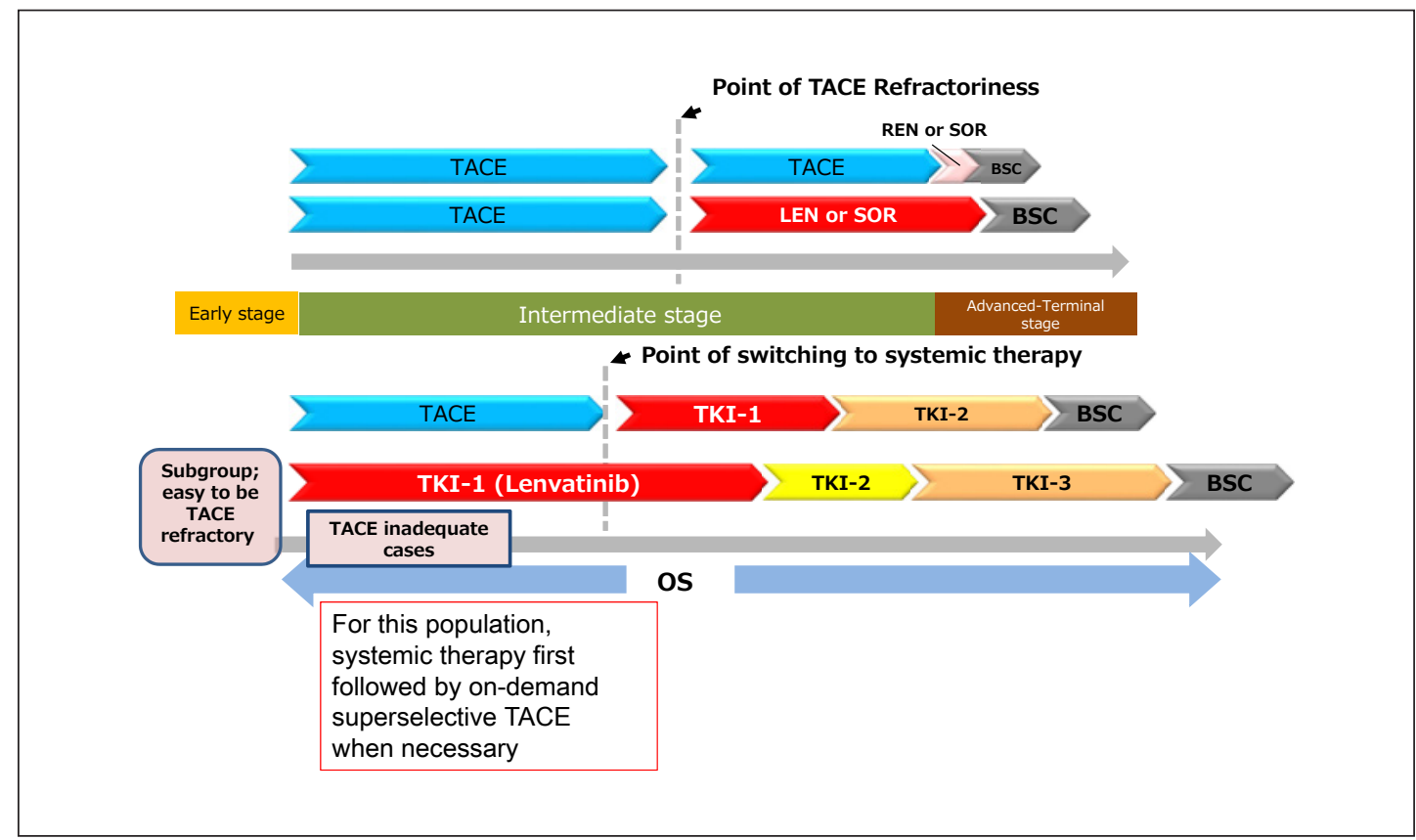

Fig. 5. Treatment strategy of intermediate-stage HCC.

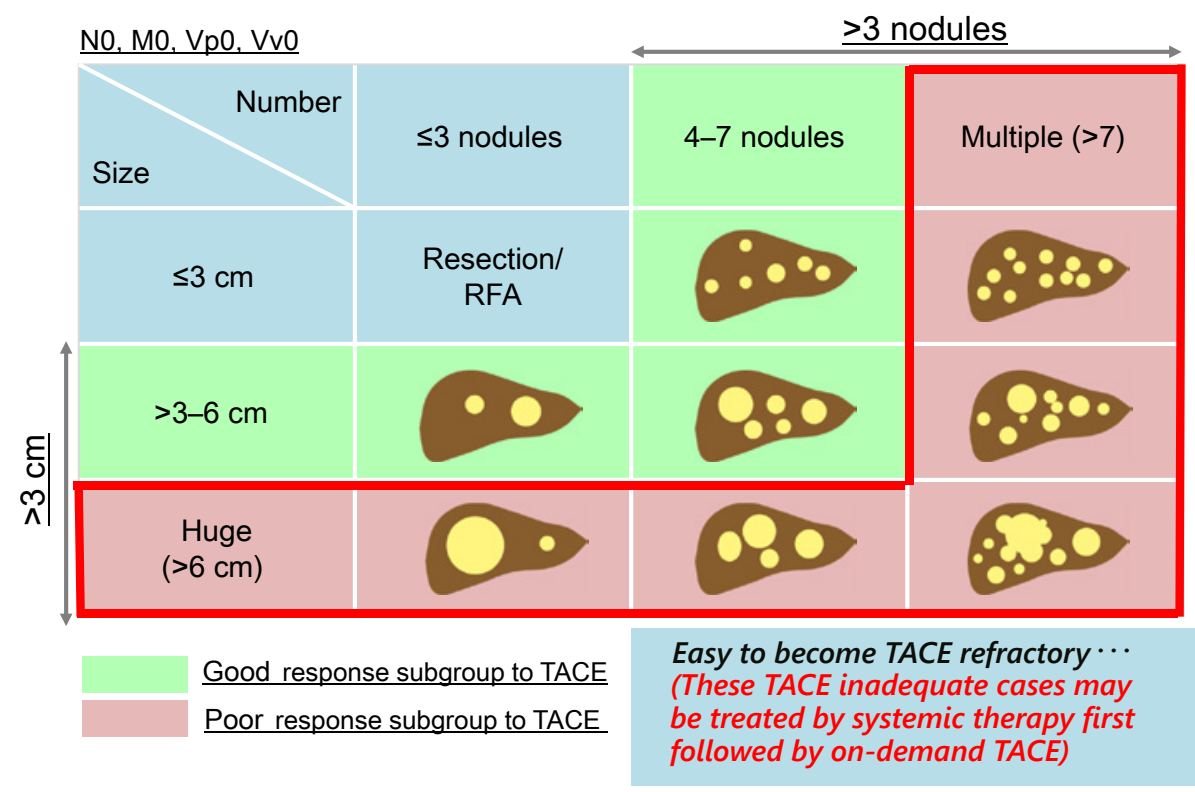

Fig. 6. Heterogeneity of intermediate-stage HCC and response to TACE. 
Table 5. New subclassification of intermediate-stage HCC: Kindai criteria (updated version of Kinki criteria)

\begin{tabular}{|c|c|c|c|c|}
\hline BCLC substage & B1 & B2 & \multicolumn{2}{|c|}{ B3 } \\
\hline Child-Pugh score & $5-7$ & $5-7$ & $8-9$ & \\
\hline Beyond Milan and up-to-7 criteria & In & Out & $\begin{array}{l}\text { Any } \\
\text { In }\end{array}$ & Out \\
\hline Sub-substage & & & B3a & $\mathrm{B} 3 \mathrm{~b}$ \\
\hline Concept of treatment strategy & Curative intent & $\begin{array}{l}\text { Noncurative } \\
\text { Palliative }\end{array}$ & $\begin{array}{l}\text { Curative intent if } \\
\text { within up-to-7 }\end{array}$ & $\begin{array}{l}\text { Palliative } \\
\text { No treatment }\end{array}$ \\
\hline Treatment option & $\begin{array}{l}\text { Resection } \\
\text { Ablation } \\
\text { Superselective cTACE }\end{array}$ & Lenvatinib (Child-Pugh A) & $\begin{array}{l}\text { Transplantation } \\
\text { Ablation } \\
\text { Superselective cTACE }\end{array}$ & $\begin{array}{l}\text { HAIC } \\
\text { Selective DEB-TACE } \\
\text { BSC }\end{array}$ \\
\hline Alternative & $\begin{array}{l}\text { DEB-TACE (large, } \\
\text { Child-Pugh 7) } \\
\text { B-TACE (fewer tumors) }\end{array}$ & $\begin{array}{l}\text { Sorafenib (Child-Pugh A) } \\
\text { TACE + sorafenib } \\
\text { DEB-TACE }(>6 \mathrm{~cm}) \\
\text { Bland TAE }(>6 \mathrm{~cm}) \text { followed by } \\
\text { targeted agents }\end{array}$ & $\begin{array}{l}\text { DEB-TACE } \\
\text { B-TACE, HAIC }\end{array}$ & BSC \\
\hline
\end{tabular}

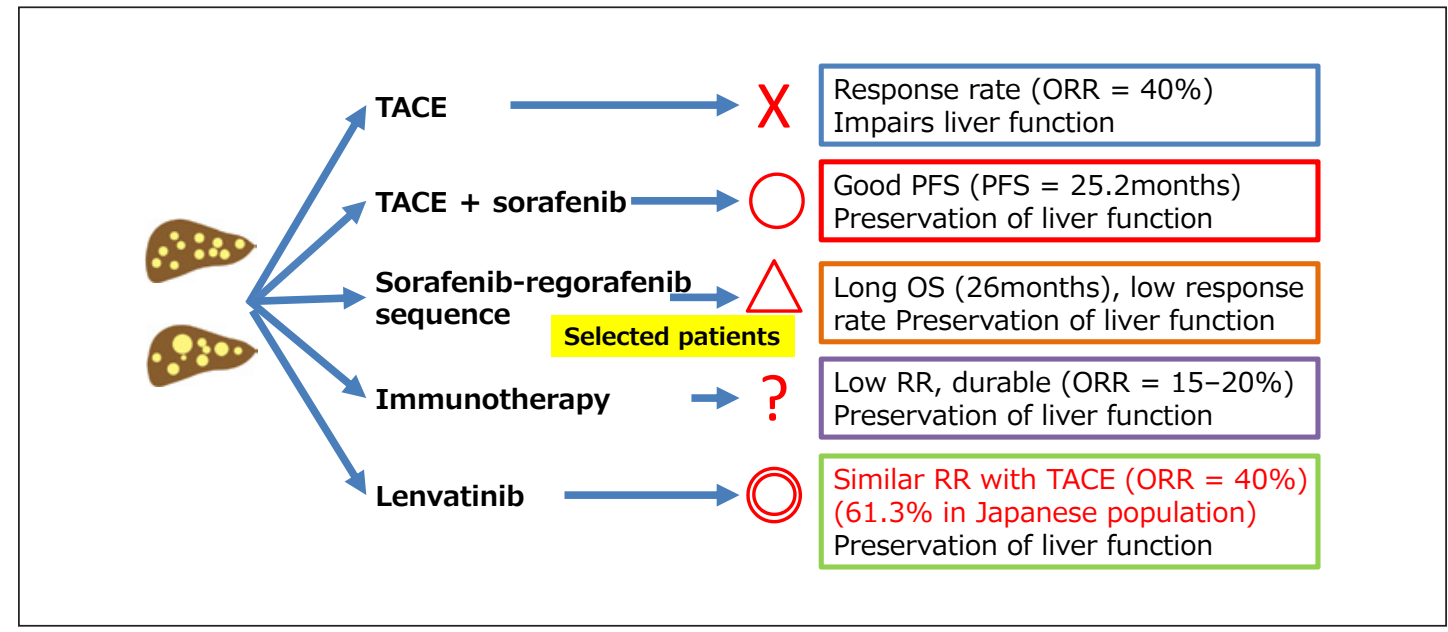

Fig. 7. Treatment strategy of bilobar multifocal intermediate-stage HCC.

(Fig. 2, 3) than the ORR by world standard of TACE, which was $42 \%$ in the placebo arm from the BRISK-TA trial or two other trials [11-13], and much higher than the ORR of 52\% for the first TACE session in real-world practice in Japan according to the OPTIMIS study (Fig. 4) [14-16]. Furthermore, progression-free survival in the intermediate-stage HCC patients was 9.1 months, which is considerably longer than that of the overall cohort at 7.4 months (Fig. 3).

Therefore, initial treatment with lenvatinib followed by on-demand TACE when necessary may be a good strategy in patients who are likely to become TACE failure in order to preserve liver function and improve OS in BCLC intermediate-stage HCC (Fig. 5, 6; Table 5). The "Kindai criteria," a new subclassification of BCLC B stage, which recently updated the original version of the Kinki criteria in 2018, is more suitable for treatment decision-making in the intermediate-stage HCC patients than the original version of the Kinki criteria (Table 5). Lenvatinib may be the first treatment option in patients with bilobar multifocal intermediate-stage HCC based on its extremely higher ORR (40.6\% in the overall cohort and $61.3 \%$ in the Japanese intermediate-stage subpopulation) than that of TACE (Figs. 3, 4, 5, 7). 


\section{Clinical Relevance of the High Response Rate}

The first important point regarding the clinical relevance of the extremely high lenvatinib response rate is that improvement of survival will be more pronounced in responders (CR + PR), and it will be achieved in a higher proportion of patients (40.6\%). The second point is that both physicians and patients are aware of the effect of the therapeutic agent, which should improve compliance and boost motivation to continue therapy. The third point is that lenvatinib is highly effective in reducing tumor size, and achievement of tumor downstaging facilitates the use of more curative treatments (e.g., resection, ablation, and superselective cTACE), which in turn improves survival even further.

Because the response rate to lenvatinib is similar to that of the world standard of TACE (42\%) according to international consensus (Fig. 2) [11], the therapeutic effect of the two modalities may be similar. As indicated, the ORR of lenvatinib is better in the Japanese subpopulation. This indicates that lenvatinib could be an alternative to TACE in a subgroup of patients with a high tumor burden of intermediate-stage tumors, such as multiple tumors in both lobes (Fig. 7) $[17,18]$. This statement does not mean that TACE should be completely abandoned. TACE can be added after initiation of lenvatinib whenever it is necessary in a superselective and on-demand manner. After progression on lenvatinib, several tyrosine kinase inhibitors such as sorafenib, cabozantinib, or ramucirumab can follow, as suggested by the American Association for the Study of Liver Diseases (AASLD) guidelines [19].

\section{Disclosure Statement:}

Masatoshi Kudo received lecture fee from Bayer, Eisai, MSD, Ajinomoto and research grant from Chugai, Otsuka, Takeda, Taiho, Sumitomo Dainippon, Daiichi Sankyo, MSD, Eisai, Bayer, AbbVie, Medico's Hirata, Astellas Pharma, Bristol-Myers Squibb and advisory consulting fee from Kowa, MSD, Bristol-Myers Squibb, Bayer, Chugai, Taiho, Eisai, Ono Pharmaceutical.

\section{References}

1 Kudo M, Finn RS, Qin S, Han KH, Ikeda K, Piscaglia F, et al. Lenvatinib versus sorafenib in first-line treatment of patients with unresectable hepatocellular carcinoma: a randomised phase 3 non-inferiority trial. Lancet. 2018 Mar;391(10126):1163-73.

2 Vincenzi B, Di Maio M, Silletta M, D’Onofrio L, Spoto C, Piccirillo MC, et al. Prognostic relevance of objective response according to EASL criteria and mrecist criteria in hepatocellular carcinoma patients treated with loco-regional therapies: A literature-based meta-analysis. PLoS One. 2015 Jul;10(7):e0133488.

3 Galle PR, Forner A, Llovet JM, Mazzaferro V, Piscaglia F, Raoul JL, et al.; European Association for the Study of the Liver. Electronic address: easloffice@easloffice.eu; European Association for the Study of the Liver. EASL clinical practice guidelines: management of hepatocellular carcinoma. J Hepatol. 2018 Jul;69(1):182-236.

4 Ronot M, Bouattour M, Wassermann J, Bruno O, Dreyer C, Larroque B, et al. Alternative Response Criteria (Choi, European association for the study of the liver, and modified Response Evaluation Criteria in Solid Tumors [RECIST]) Versus RECIST 1.1 in patients with advanced hepatocellular carcinoma treated with sorafenib. Oncologist. 2014 Apr;19(4):394-402.

5 Arizumi T, Ueshima K, Chishina H, Kono M, Takita M, Kitai S, et al. Duration of stable disease is associated with overall survival in patients with advanced hepatocellular carcinoma treated with sorafenib. Dig Dis. 2014; 32(6):705-10.

6 Edeline J, Boucher E, Rolland Y, Vauléon E, Pracht M, Perrin C, et al. Comparison of tumor response by Response Evaluation Criteria in Solid Tumors (RECIST) and modified RECIST in patients treated with sorafenib for hepatocellular carcinoma. Cancer. 2012 Jan;118(1):147-56.

7 Takada J, Hidaka H, Nakazawa T, Kondo M, Numata K, Tanaka K, et al. Modified response evaluation criteria in solid tumors is superior to response evaluation criteria in solid tumors for assessment of responses to sorafenib in patients with advanced hepatocellular carcinoma. BMC Res Notes. 2015 Oct; 8:609.

8 Lencioni R, Montal R, Torres F, Park JW, Decaens T, Raoul JL, et al. Objective response by mRECIST as a predictor and potential surrogate end-point of overall survival in advanced HCC. J Hepatol. 2017 Jun;66(6): 1166-72. 
9 Meyer T, Palmer DH, Cheng AL, Hocke J, Loembé AB, Yen CJ. mRECIST to predict survival in advanced hepatocellular carcinoma: analysis of two randomised phase II trials comparing nintedanib vs sorafenib. Liver Int. 2017 Jul;37(7):1047-55.

10 Kudo M, Ueshima K, Yokosuka O, Ogasawara S, Obi S, Izumi N, et al.; SILIUS study group. Sorafenib plus low-dose cisplatin and fluorouracil hepatic arterial infusion chemotherapy versus sorafenib alone in patients with advanced hepatocellular carcinoma (SILIUS): a randomised, open label, phase 3 trial. Lancet Gastroenterol Hepatol. 2018 Jun;3(6):424-32.

11 Kudo M, Han G, Finn RS, Poon RT, Blanc JF, Yan L, et al. Brivanib as adjuvant therapy to transarterial chemoembolization in patients with hepatocellular carcinoma: A randomized phase III trial. Hepatology. 2014 Nov; 60(5):1697-707.

12 Lencioni R, Llovet JM, Han G, Tak WY, Yang J, Guglielmi A, et al. Sorafenib or placebo plus TACE with doxorubicin-eluting beads for intermediate stage HCC: the SPACE trial. J Hepatol. 2016 May;64(5):1090-8.

13 Meyer T, Fox R, Ma YT, Ross PJ, James MW, Sturgess R, et al. Sorafenib in combination with transarterial chemoembolisation in patients with unresectable hepatocellular carcinoma (TACE 2): a randomised placebocontrolled, double-blind, phase 3 trial. Lancet Gastroenterol Hepatol. 2017 Aug;2(8):565-75.

14 Yamashita T, Kudo M, Ikeda K, Izumi N, Ikeda M, Okusaka T, et al. Analysis of Japanese subpopulation form reflect trial. The 18th annual meeting of Japan Association of Molecular Targeted Therapy for HCC; 2018 July 14, Tokyo.

15 Kudo M. An international observational study to assess the real-world use of transarterial chemoembolization (TACE) in patients with hepatocellular carcinoma (HCC): The final analysis and Japanese subpopulation analysis of OPTIMIS. The 54th annual meeting of Liver Cancer Study Group of Japan; 2018 June 28, Kurume.

16 Ogasawara S, Chiba T, Ooka Y, Kanogawa N, Motoyama T, Suzuki E, et al. Efficacy of sorafenib in intermediatestage hepatocellular carcinoma patients refractory to transarterial chemoembolization. Oncology. 2014; 87(6):330-41.

17 Kudo M. A new era of systemic therapy for hepatocellular carcinoma with regorafenib and lenvatinib. Liver Cancer. 2017 Jun;6(3):177-84.

18 Kudo M. Lenvatinib in advanced hepatocellular carcinoma. Liver Cancer. 2017 Nov;6(4):253-63.

19 Marrero JA, Kulik LM, Sirlin C, Zhu AX, Finn RS, Abecassis MM, et al. Diagnosis, Staging, and Management of Hepatocellular Carcinoma: 2018 Practice Guidance by the American Association for the Study of Liver Diseases. Hepatology. 2018 Aug;68(2):723-50. 